\title{
A multi-pronged investigation into the effect of glucose starvation and culture duration on fed-batch $\mathrm{CHO}$ cell culture
}

Fan, Yuzhou; Jimenez Del Val, loscani; Müller, Christian; Lund, Anne Mathilde; Wagtberg Sen, Jette; Rasmussen, Søren Kofoed; Kontoravdi, Cleo; Baycin-Hizal, Deniz; Betenbaugh, Michael J.; Weilguny, Dietmar

Total number of authors:

11

Published in:

Biotechnology and Bioengineering (Print)

Link to article, DOI:

10.1002/bit.25620

Publication date:

2015

Document Version

Peer reviewed version

Link back to DTU Orbit

Citation (APA):

Fan, Y., Jimenez Del Val, I., Müller, C., Lund, A. M., Wagtberg Sen, J., Rasmussen, S. K., Kontoravdi, C.,

Baycin-Hizal, D., Betenbaugh, M. J., Weilguny, D., \& Andersen, M. R. (2015). A multi-pronged investigation into the effect of glucose starvation and culture duration on fed-batch $\mathrm{CHO}$ cell culture. Biotechnology and Bioengineering (Print), 112(10), 2172-2184. https://doi.org/10.1002/bit.25620

\section{General rights}

Copyright and moral rights for the publications made accessible in the public portal are retained by the authors and/or other copyright owners and it is a condition of accessing publications that users recognise and abide by the legal requirements associated with these rights.

- Users may download and print one copy of any publication from the public portal for the purpose of private study or research.

- You may not further distribute the material or use it for any profit-making activity or commercial gain

- You may freely distribute the URL identifying the publication in the public portal 


\section{A multi-pronged investigation into the effect of glucose starvation and culture duration on fed-batch $\mathrm{CHO}$ cell culture ${ }^{\dagger}$}

Yuzhou Fan ${ }^{1,2}$, Ioscani Jimenez Del Val ${ }^{3}$, Christian Müller ${ }^{2}$, Anne Mathilde Lund ${ }^{1}$, Jette Wagtberg Sen ${ }^{2}$, Søren Kofoed Rasmussen ${ }^{2}$, Cleo Kontoravdi ${ }^{3}$, Deniz Baycin-Hizal ${ }^{4}$, Michael J. Betenbaugh $^{4}$, Dietmar Weilguny ${ }^{2 *}$ and Mikael Rørdam Andersen ${ }^{1 *}$

${ }^{1}$ Network Engineering of Eukaryotic Cell Factories, Department of Systems Biology, Technical University of Denmark, Building 223, 2800 Kgs. Lyngby, Denmark

${ }^{2}$ Symphogen A/S, Pederstrupvej 93, 2750 Ballerup, Denmark

${ }^{3}$ Center for Process Systems Engineering, Department of Chemical Engineering, Imperial College London, South Kensington Campus, London SW7 2AZ, UK

${ }^{4}$ Department of Chemical and Biomolecular Engineering, Johns Hopkins University, Baltimore, MD 21218, USA

*Corresponding author.

Address correspondence to Mikael Rørdam Andersen, Department of Systems Biology, Technical University of Denmark, Building 223, 2800 Kgs. Lyngby, Denmark; +4545252675; mr@bio.dtu.dk

Address correspondence to Dietmar Weilguny, Cell line and Upstream, Symphogen A/S, Pederstrupvej 93, 2750 Ballerup, Denmark; +4588382683; dw@symphogen.com

Short running title: A multi-pronged investigation into fed-batch $\mathrm{CHO}$ cell culture

\section{Keywords}

Chinese hamster ovary cells; fed-batch; monoclonal antibody; glycosylation; proteomics; glucose starvation; culture duration.

${ }^{\dagger}$ This article has been accepted for publication and undergone full peer review but has not been through the copyediting, typesetting, pagination and proofreading process, which may lead to differences between this version and the Version of Record. Please cite this article as doi: [10.1002/bit.25620]

Additional Supporting Information may be found in the online version of this article.

This article is protected by copyright. All rights reserved

Received December 2, 2014; Revision Received March 1, 2015; Accepted April 7, 2015 


\section{Abstract}

In this study, omics-based analysis tools were used to explore the effect of glucose starvation and culture duration on monoclonal antibody $(\mathrm{mAb})$ production in fed-batch $\mathrm{CHO}$ cell culture to gain better insight into how these parameters can be controlled to ensure optimal mAb productivity and quality. Titer and N-glycosylation of mAbs, as well as proteomic signature and metabolic status of the production cells in the culture were assessed.

We found that the impact of glucose starvation on the titer and N-glycosylation of mAbs was dependent on the degree of starvation during early stationary phase of the fed-batch culture. Higher degree of glucose starvation reduced intracellular concentrations of UDP-GlcNAc and UDP-GalNAc, but increased the levels of UDP-Glc and UDP-Gal. Increased GlcNAc and Gal occupancy correlated well with increased degree of glucose starvation, which can be attributed to the interplay between the dilution effect associated with change in specific productivity of mAbs and the changed nucleotide sugar metabolism.

Herein, we also show and discuss that increased cell culture duration negatively affect the maturation of glycans. In addition, comparative proteomics analysis of cells was conducted to observe differences in protein abundance between early growth and early stationary phases. Generally higher expression of proteins involved in regulating cellular metabolism, extracellular matrix, apoptosis, protein secretion and glycosylation was found in early stationary phase. These analyses offered a systematic view of the intrinsic properties of these cells and allowed us to explore the root causes correlating culture duration with variations in the productivity and glycosylation quality of monoclonal antibodies produced with $\mathrm{CHO}$ cells. This article is protected by copyright. All rights reserved 


\section{Introduction}

Over the last decade Chinese hamster ovary (CHO) cells have been the predominant expression system used in the pharmaceutical bioprocessing of recombinant monoclonal antibodies (mAbs) due to their adaptability to industrial manufacturing environment and posttranslational modification compatibility with human patients (Lim et al. 2010). Fed-batch culture has become a widely used approach for mAb production because of its value in extending the viable and productive phase of the culture (Rouiller et al. 2013).

The manufacturing process is typically optimized for increasing the productivity of mAbs, but this often increases the risk of compromising the critical quality attributes of the recombinant product. A number of strategies aiming at improving final titer have been proposed. For example, limiting the feed of glucose to minimize lactate accumulation (Dean and Reddy 2013; Gagnon et al. 2011) and extending culture duration to prolong the production window (Druz et al. 2013; Robinson et al. 1994), have been successfully implemented. However, all these strategies require precise control of the production process. The level of glucose limitation is crucial for the process, since it may cause undesired glucose starvation and lead to reduced cell growth and productivity (Hu et al. 1987) and altered Nglycosylation quality (Liu et al. 2014). Extended culture duration may also affect the mAb quality in terms of N-glycosylation patterns (Pacis et al. 2011). N-glycosylation of mAbs affects their pharmacokinetic characteristics and efficacy as a drug, including clearance rate, stability, immunogenicity, antibody-dependent cellular cytoxicity (ADCC) and complementdependent cytoxicity (CDC) (Goetze et al. 2011; Hossler et al. 2009; Jefferis 2012; Raju 2008; Zheng et al. 2011).

Recently, CHO cell bioprocessing entered the omics era (Kildegaard et al. 2013), thanks to the availability of the CHO-K1 and Chinese hamster genome sequences, along with draft genomes of multiple cell lines (Cao et al. 2012; Lewis et al. 2013; Xu et al. 2011). This has 
made other omics-based technologies more readily available for $\mathrm{CHO}$ cell culture, including RNA-sequencing transcriptomics analysis (McGettigan 2013) and tandem mass spectrometry-based proteomics analysis (Baycin-Hizal et al. 2012). In order to increase the understanding of $\mathrm{CHO}$ cell physiology to better control the quality attributes of mAbs, a multi-pronged approach that integrate data from cell culture behavior, metabolism, mAb quality and omics-based phenotyping will become a trend for $\mathrm{CHO}$ cell culture process development in the future.

This study is, to our best knowledge, the first time a multi-pronged approach has been used to investigate the effect of glucose starvation and culture duration on mAb production in fedbatch $\mathrm{CHO}$ cell culture. Here, we aim to understand how the titer and N-glycosylation of the $\mathrm{mAb}$ product, as well as the proteomic signature and the intrinsic properties of the cells, are affected by changing these process parameters. The results presented herein provide mechanistic insight into how these process parameters influence mAb productivity and quality, and thus should aid in the identification of an appropriate operating windows for glucose limitation without running into glucose starvation and of the optimal harvest time.

\section{Materials and methods}

\section{Cell culture and fed-batch process}

Cell line A, an in-house CHO DG44 cell line producing mAb A was used as model cell line in this study. Cells were maintained in proprietary serum-free basal medium in shake flask at $37^{\circ} \mathrm{C}, 5 \% \mathrm{CO}_{2}, 200 \mathrm{rpm}$ prior to the fed-batch process.

Fed-batch culture was carried out in $500 \mathrm{ml}$ shake flasks (working volume $50-100 \mathrm{ml}$ ) at $37^{\circ} \mathrm{C}, 5 \% \mathrm{CO}_{2}, 200 \mathrm{rpm}$ with an initial seeding density of $4 \times 10^{5}$ viable cells $/ \mathrm{mL}$ and temperature shift from $37^{\circ} \mathrm{C}$ to $33.5^{\circ} \mathrm{C}$ on day 5. Proprietary feed was added to the culture on days $2,5,7,9$ and 12 (10\% of the initial culture volume). Glucose concentration was adjusted to $33 \mathrm{mM}$ on day 5 and to $50 \mathrm{mM}$ on day 12 . Cell culture was sampled before feeding on days 
2, 5, 7, 9, 12 and 14 for monitoring cell growth (Vi-CELL XR, Beckman Coulter, Brea, CA), cell metabolism (Bioprofile 100plus, Nova BioMedical, Waltham, WA) and mAb production (Octet QK384 equipped with Protein A biosensors, ForteBio, Menlo Park, CA). Sampling for intracellular nucleotide sugar quantification and mAb glycoprofiling was performed on days 2, 5, 9 and 12. Harvesting criteria for the culture was considered to be either when cell viability fell below $70 \%$ or on day 14 , whichever occurred first. Four different fed-batch processes were performed in duplicate: severe glucose starvation (SGS), high glucose starvation (HGS), low glucose starvation (LGS) and no glucose starvation (NGS). In each of these processes, glucose concentration was set to $11 \mathrm{mM}$ (SGS), 22mM (HGS), 33mM (LGS) and 50mM (NGS) on day 9 of the fed-batch culture. Additional sampling for comparative proteomics analysis was performed on days 2 and 9 of the NGS process.

\section{Nucleotide sugar analysis}

Nucleotide sugar analysis was performed on harvested cell pellets using acetonitrile extraction followed by high-performance anion-exchange (HPAEC) HPLC as described previously (Fan et al. 2015; Jimenez Del Val et al. 2013).

\section{Semi-high throughput mAb purification}

The supernatant harvested from cell culture was filtered through a $0.22 \mu \mathrm{m}$ filter (Millipore, Billerica, MA) and applied onto a Protein A HP MultiTrap ${ }^{\mathrm{TM}}$ 96-well filter plate (GE Healthcare, Fairfield, CA) which had been previously equilibrated with PBS following the manufacturer's instructions. Elution was performed using $0.1 \mathrm{M}$ citrate buffer $(\mathrm{pH}=3.5$, Sigma-Aldrich). The eluate was immediately transferred to a $\mathrm{Zeba}^{\mathrm{TM}}$ spin desalting plate (Thermo Scientific, Waltham, MA) previously equilibrated with a $10 \mathrm{mM}$ citrate, $150 \mathrm{mM}$ $\mathrm{NaCl}(\mathrm{pH}=6.0)$ buffer (Sigma-Aldrich, St. Louis, MO). Purified mAb concentration was measured using a NanoDrop ND-1000 system (Thermo Scientific) prior to sample storage at $-20^{\circ} \mathrm{C}$. 


\section{mAb Glycoprofiling}

mAb Glycoprofiling was performed with an in-house HPLC analysis method using InstantAB labeled (Prozyme, Hayward, CA) glycans (Fan et al. 2015).

\section{Statistical analysis of glycoform distributions}

Differences among the glycoform distributions were evaluated by comparing the mean obtained from two independent experiments. Depending on equality of variances, different post-hoc tests were performed to assess the statistical significance of the differences among the means. First, the variances of each treatment were compared using Levene's test. If the variances were observed to be equal, a one-way ANOVA was performed to evaluate the differences between the means of the treatments. Where the ANOVA yielded statistically significant differences $\left(\mathrm{p}_{\mathrm{ANOVA}}<0.05\right)$, Tukey's honest significant difference test was performed post-hoc for pairwise comparisons. For data where the variances were found to be unequal, a one-way Welch's ANOVA was performed, and if this analysis yielded statistical significance $\left(\mathrm{p}_{\mathrm{WELCH}}<0.05\right)$, the Games-Howell post hoc test was performed for pairwise comparisons. All statistical analysis was performed using the IBM SPSS Statistics software, v.20 (SPSS Inc. 2011).

\section{Sample preparation for proteomics analysis}

Two biological replicates from days 2 and 9 of the NGS fed batch process were subjected to proteomics analysis using iTRAQ (isobaric Tags for Relative and Absolute Quantification) labeling mass spectrometry (Aggarwal et al. 2006; Pottiez et al. 2012). The harvested cells were washed with ice-cold PBS (Invitrogen, Life Technologies, Carlsbad, CA), flash-frozen in liquid nitrogen and stored at $-80^{\circ} \mathrm{C}$ prior to cell lysis. For lysis, the cells were thawed and immediately resuspended in SDS-lysis buffer (2\% SDS (w/v), 1mM EDTA and 0.1mM phenylmethylsulfonyl fluoride [PMFS], $\mathrm{pH}=8$ adjusted with triethylammonium bicarbonate [TEABC], Sigma-Aldrich) and sonicated on ice three times for 30 seconds with a probe 
sonicator. The total protein concentration of the lysate was measured with the BCA assay (Thermo scientific).

The lysates were then reduced by incubation in a final concentration of $4.5 \mathrm{mM}$ Tris-(2carboxyethyl) phosphine (TCEP, Sigma-Aldrich) at $60^{\circ} \mathrm{C}$ for 1 hour and subsequently alkylated by incubation in a final concentration of $8.3 \mathrm{mM}$ methyl methanethiosulfonate (MMTS, Sigma-Aldrich) at room temperature in the dark for $30 \mathrm{~min}$ using a modified filter-

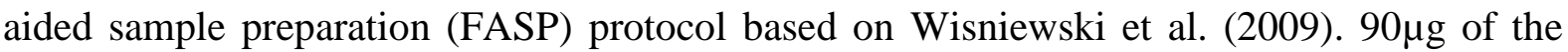
obtained protein from each sample were diluted with 9M Sequanal grade urea (Thermo scientific) to obtain a final SDS concentration of $0.09 \%(\mathrm{w} / \mathrm{v})$. This mixture was incubated at room temperature in the dark for 1 hour after which the low-molecular-weight substances were removed by ultracentrifugation using a $10 \mathrm{KDa}$ cutoff $0.5 \mathrm{ml}$ Amicon filter (Millipore). The retained proteins were digested by incubation with $50 \mu \mathrm{L}$ of LysC digestion buffer (50 mM TEABC, $\mathrm{pH}=8$ ) containing $4.5 \mu \mathrm{g}$ of LysC enzyme (Wako Pure Chemical Industries, Japan) at $37^{\circ} \mathrm{C}$ for 4 hours and additional incubation with $350 \mu \mathrm{L}$ trypsin LysC digestion buffer $(50 \mathrm{mM}$ TEABC, $\mathrm{pH}=8)$ containing $10 \mu \mathrm{g}$ trypsin enzyme (Promega Corporation, Madison, WI) at $37^{\circ} \mathrm{C}$ overnight. The digested peptides were dried using SpeedVac (Savant, Thermo Scientific) prior to iTRAQ labelling. The iTRAQ 8-plex reagent was dissolved in $50 \mu \mathrm{L}$ of isopropanol following the manufacturer's instructions (AB Sciex, Framingham, MA). Each dried peptide sample was dissolved in a mixture of $17 \mu \mathrm{L} \mathrm{H} 2 \mathrm{O}, 20 \mu \mathrm{L} 0.5 \mathrm{M}$ TEABC and $50 \mu \mathrm{L}$ of iTRAQ 8-plex reagent solution and incubated for 2 hours at room temperature in the dark. Peptides from different samples with their unique iTRAQ labeling were mixed, dried and resuspended into $1 \mathrm{~mL}$ of $10 \mathrm{mM}$ TEABC prior to peptide fractionation using basic $\mathrm{pH}$ reversed-phase liquid chromatography (bRPLC). 


\section{Fractionation of peptides}

The bRPLC method was performed to improve identification of unique peptides in the sample as was described byBaycin-Hizal et al. (2012). Peptides were fractionated on an XBridge C18 Column (5 $\mu \mathrm{m}, 2.1$ x $100 \mathrm{~mm}$, Waters, Milford, MA) with an XBridge C18 Guard Column (5 $\mu \mathrm{m}, 2.1$ x $10 \mathrm{~mm}$, Waters), using an Agilent HPLC system consisting of a 1100 series binary pump, a 1200 series UV detector and a 1200 series micro-fraction collector. Fractionation of peptides was carried out by a linear gradient (T0 $\min =10 \% \mathrm{~B}, \mathrm{~T} 10$ $\min =10 \% \mathrm{~B}, \mathrm{~T} 50 \mathrm{~min}=35 \% \mathrm{~B}, \mathrm{~T} 50.1 \mathrm{~min}=70 \% \mathrm{~B}, \mathrm{~T} 60 \mathrm{~min}=70 \% \mathrm{~B}, \mathrm{~T} 60,1 \mathrm{~min}=100 \% \mathrm{~B}$, $\mathrm{T} 70 \min =100 \% \mathrm{~B}, \mathrm{~T} 70.1 \mathrm{~min}=10 \% \mathrm{~B}, \mathrm{~T} 95 \mathrm{~min}=10 \% \mathrm{~B})$ between solvent $\mathrm{A}(10 \mathrm{mM}$ TEABC, Sigma-Aldrich) and solvent B (10 mM TEABC in 90\%v/v Acetonitrile, SigmaAldrich) with a flow rate of $250 \mu \mathrm{L} / \mathrm{min} .84 \mathrm{bRP}$ fractions were collected and re-combined into 24 fractions and then dried in a SpeedVac (Savant, Thermo Scientific) prior to liquid chromatography/tandem mass spectrometry (LC-MS/MS) analysis.

\section{LC-MS/MS analysis}

The LC-MS/MS analysis of the different fractions of the peptides was performed using an LTQ Orbitrap Velos MS/MS in FTFT (Thermo Scientific) interfaced with a 2D nanoLC system (Eksigent, AB Sciex), as described previously (Baycin-Hizal et al. 2012), but with the following modified parameters. Precursor and fragment ions were explored in tandem MS analysis at a resolution of 30000 and 15000, respectively. Survey scans (full ms) were acquired on the Orbitrap within an $\mathrm{m} / \mathrm{z}$ range between 350-1700Da. Precursor ions were individually isolated with a 1.2Da window and fragmented (MS/MS) using $40 \%$ collision energy in order to achieve higher collision dissociation (HCD) activation. The MS/MS spectra were analyzed using the Mascot software (v2.2.2, Matrix Science, London, UK) in the framework of ProteomeDiscoverer v1.4 (PD1.3; Thermo Scientific) with fixed modifications of N-terminal 8-plex-iTRAQ labeling and cysteine methylthiolation and 
variable modifications of methionine oxidation and 8-plex-iTRAQ labeling of tyrosine and lysine.

\section{MS data analysis}

The obtained MS data was compared against the cricetulus_g_v2 custom database, which was constructed using the RefSeq annotation of the $\mathrm{CHO}$ genomic sequence downloaded in October, 2013. Protein identification was performed using Mascot v2.2.2 (Matrix Science) where the searches were processed with a confidence threshold of $1 \%$ False Discovery Rate (FDR). Protein ratios were calculated based on the median value of the unique peptide ratios.

\section{Comparative proteomics analysis}

A BLASTp search of all identified proteins was performed against the mouse, human and rat RefSeq databases (accessed on November, 2013) in order to find the closest homologous proteins (lowest E-value) in these species. Identifiers, including RefSeq Protein Accession, ENSEMBL gene ID, UNIPROT accession and Agilent ID for each protein were subsequently obtained using the Gene ID conversion Tool from the DAVID database (Huang da et al. 2009a; Huang da et al. 2009b) (from November, 2013). Gene set enrichment analysis (GSEA) (Subramanian et al. 2005) was performed on the proteins that exhibited differential expression between days 2 and 9. The resulting data were used to identify the up and down-regulated gene sets (between 15 and 500 genes per set) between days 2 and 9 of the NGS fed-batch process. This analysis was performed using both the functional database (a combination of Biocarta, KEGG and Reactome databases) and the gene ontology database (downloaded from Molecular Signatures Database v4.0, http://www.broadinstitute.org/gsea/msigdb/index.jsp). Leading edge genes (genes that are core representatives of their gene set with FDR q-value cutoff of 0.25 ) were identified using Leading-edge analysis. An enrichment map (Merico et al. 2010) of the gene clusters were obtained in Cytoscape v3.1.1 using the GSEA results as input, a p-value cutoff of 0.05 and an FDR q-value cutoff of 0.25. A direct search using all 
identified proteins from MS analysis against an in-house reconstruction of the CHO secretory pathway network (Table SX) was performed with a $\log 2$ expression cut off of \pm 0.8 and a pvalue cutoff of 0.05 in order to analyze the secretion machinery of the cells. Moreover, all identified proteins that are involved in nucleotide sugar biosynthesis pathway and glycan biosynthesis pathway were sorted out and evaluated.

\section{Results and Discussion}

During fed-batch manufacturing of mAbs, glucose concentration and culture duration are considered to be critical parameters for both productivity and quality (Pacis et al. 2011; Xie et al. 1997). Therefore, lack of control in these parameters is always risky for mAb manufacture. Here, we investigate the effect of glucose starvation during early stationary phase of fed-batch culture and the effect of culture duration on mAb productivity and glycosylation. Our results contribute to further understand how glucose starvation and culture duration impact $\mathrm{CHO}$ cell physiology in fed-batch culture processes and yields insight into potential metabolic and/or proteomic causes for these effects.

\section{Effect of glucose starvation}

Culture performance and $\mathrm{mAb}$ productivity of four culture processes with different degrees of glucose starvation (SGS, HGS, LGS and NGS) are shown in Figure 1 and are summarized in Table I. As would be expected, glucose starvation during early stationary phase resulted in earlier onset of cell death (Figures $1 \mathrm{~A}$ and B), reduced integral viable cell concentration (IVC) (Figure $1 \mathrm{C}$ ), lactate depletion (Figure $1 \mathrm{E}$ ), and increased accumulation of $\mathrm{NH}_{4}^{+}$ (Figure $1 \mathrm{~F}$ ). Additionally, the level of glucose starvation negatively correlated with mAb titer (Figure $1 \mathrm{C}$ ) and specific productivity $\left(q_{p}\right)$ (Figure $1 \mathrm{C}$ slope of the curves).

Nucleotide sugars (NSs) are metabolites that are required as substrates for the elongation of oligosaccharide chains during the process of glycosylation. Their concentrations in the cell have been demonstrated to be one of the major causes of alterations in $\mathrm{mAb}$ glycopatterns 
(Chee Furng Wong et al. 2005; Fan et al. 2015; Wong et al. 2010b). It has been previously suggested that glucose depletion can reduce the biosynthesis of nucleotide sugars (Kochanowski et al. 2008). In accordance with this hypothesis, we observed reduced (LGS) or even fully depleted (HGS and SGS) intracellular concentrations of uridine diphosphate Nacetylglucosamine (UDP-GlcNAc) and uridine diphosphate N-acetylgalactosamine (UDPGalNAc) when glucose availability was limited during early stationary phase of the fed-batch culture (Figure 2 - bottom). Counterintuitively though, considerable accumulation of uridine diphosphate glucose (UDP-Glc) and uridine diphosphate galactose (UDP-Gal) was observed after glucose starvation was induced at day 9 of culture (Figure $2-$ top). Although this finding may be seen as conflicting, a clear explanation can be found when considering the steps involved in NS biosynthesis and glutamine metabolism in CHO cells. Figure 2 shows a simplified metabolic diagram for NS biosynthesis from glucose and glutamine (Gln) as primary substrates. There, we see that Fru-6P and Gln are combined to yield glucosamine 6-P (GlcN-6P), which eventually is converted to UDP-GlcNAc. Glutamine, in turn, has been widely reported to be consumed as an important carbon and energy source by CHO cells (Ahn and Antoniewicz 2013; Dean and Reddy 2013; Templeton et al. 2013; Young 2013). These authors have reported that considerable amounts of the Gln consumed during CHO cell culture is deamidated to yield ammonia and glutamate (Glu), the latter of which is then converted to TCA cycle intermediates such as oxaloacetate and $\alpha$-ketoglutarate $(\alpha-\mathrm{KG})$. It is likely that under glucose starvation, glutamine and other amino acids uptake towards TCA cycle intermediates is increased in an attempt to sustain cellular energetic requirements, and that this increased glutaminolysis towards TCA cycle intermediates translates into a decreased flux of Gln towards GlcN-6P and eventual UDP-GlcNAc formation. Simultaneously, the flux of glucose that is not being converted to UDP-GlcNAc due to lack of Gln availability may be funneled towards UDP-Glc and UDP-Gal formation, possibly 
generating the observed accumulation in the HGS and SGS cultures. This mechanism is further substantiated by the observed increase in both Glu and $\mathrm{NH}_{4}{ }^{+}$concentration seen in Figures $1 \mathrm{E}$ and $\mathrm{H}$, respectively, and a considerably higher Gln uptake rate in processes SGS and HGS.

Alongside the possible metabolic effects described above, the consumption rate of the NSs for the glycosylation reactions must be considered. It is possible that UDP-Gal accumulates in the HGS and SGS cases because they present lower specific mAb productivity (Figure 1 C). If the drop in $q_{p}$ for these cases is higher than the drop in UDP-Gal biosynthesis, this NS would accumulate. Similarly, the NGS and LGS cases present accumulation of UDP-GlcNAc (Figure 2), higher Man 5 (Figure 3 A) and lower GlcNAc occupancy (Figure S1 A) after glucose starvation is induced. It is possible that UDP-GlcNAc accumulates in these cases because consumption of this NS towards glycosylation is lower. These results highlight the interplay between nucleotide sugar metabolism and recombinant protein productivity.

The considerable changes in glycoform distribution observed between days 5 and 9 of culture reduce visibility of changes in glycosylation after glucose starvation is induced in Figures 3 and 4. However, a positive correlation between the degree of glucose starvation and the maturation of glycans was observed in repeated experiments.

In Table II, the fractions of secreted $\mathrm{mAb}$ change during the intervals depend on variations in specific productivity $\left(q_{p}\right)$, which are most likely a consequence of glucose availability for each case. Specifically, a smaller fraction of the total mAb produced is being secreted by the HGS and SGS cases in the interval where glucose limitation was introduced (9 to $12 \mathrm{~d})$. When considering these changes in $q_{p}$ with respect to glucose availability, the reason why SGS yields a distribution with more highly processed glycoforms at day 12 is that during the starvation period, only $15.2 \% \pm 0.5 \%$ of the total amount of $\mathrm{mAb}$ is produced. This lower fraction is diluted with the product that has been secreted up to that point in culture $(84.8 \% \pm$ 
$0.5 \%$ ), and it is the dilution effect which leads to lower apparent decreases in mature glycoforms between days 9 and 12 (Figure 4). In contrast, a larger fraction of the total $\mathrm{mAb}$ is produced for the cases of less glucose starvation during the starvation period and thus, the dilution effect associated with changes in $q_{p}$ may mask the impact of cellular metabolism (via nucleotide sugar biosynthesis) on glycosylation.

In order to account for the effect of $q_{p}$ on the glycan distributions after glucose limitation, the relative amount of each mAb glycoform produced $\left(f_{i}\right)$ during the interval was calculated based on a material balance for glycoform $i\left(m A b_{i}\right)$ over the starvation period:

$f_{j}=\frac{\left[m A b_{i}\right]\left(t_{2}\right)-\left[m A b_{i}\right]\left(t_{1}\right)}{q_{p} x_{v}\left(t_{2}-t_{1}\right)} \ldots$ Eq. 1

Where $q_{p}$ is the mAb specific productivity and $X_{v}$ is the average cell density over the time interval (from $t 1=9 \mathrm{~d}$ to $\mathrm{t} 2=12 \mathrm{~d}$ for the starvation period). And considering that $q_{p} X_{v}\left(t_{2}-t_{1}\right)=\left[m A b_{\tau o t}\right]\left(t_{2}\right)-\left[m A b_{\tau_{o t}}\right]\left(t_{1}\right)$, we find a simpler expression for $f_{i}$ : $f_{j}=\frac{\left[m A b_{1}\right]\left(t_{2}\right)-\left[m A b_{1}\right]\left(t_{1}\right)}{\left[m A b_{T o t}\right]\left(t_{2}\right)-\left[m A b_{T o t}\right]\left(t_{1}\right)} \ldots$ Eq. 2

In equation $2, f_{i}$ represents the mass fraction of mAb glycoform $i$ produced relative to the total amount of mAb secreted during the time interval. Because Fc glycan variation accounts for very small changes in mAb molecular weight $(<0.05 \%), f_{i}$ was assumed to be a close approximation to the mole fraction of mAb glycoform $i$ per total moles of mAb produced over the starvation interval.

Figure 4 shows the fractions calculated with equation 2 for the interval before (day 5 to 9 ) and after (day 9 to 12) glucose starvation is induced for all degrees of glucose limitation (NGS, LGS, HGS and SGS). As expected, there are no statistical differences between the cases prior to glucose starvation (day 5 to 9) given that up to this point, all cultures were performed under similar conditions. However, statistically significant differences can be 
observed for Man5, G1F and G2F between the time intervals and among certain glucose starvation conditions during the 9 to $12 \mathrm{~d}$ interval.

Figure 4A shows that more Man5 is secreted during the 9 to $12 \mathrm{~d}$ interval for all but the SGS culture. Within this interval, and depending on the different glucose starvation conditions, there is a decreasing trend where less Man5 is produced at higher glucose starvation. These results are reflected in GlcNAc occupancy (Figure 4, bottom row).

When considering the intracellular UDP-GlcNAc concentrations presented in Figure 2, it is evident that lack of availability of this NS is not causing the increase in Man5 secretion for the NGS and LGS cultures. This is further substantiated by the small decrease in G0F glycoform secretion after glucose starvation for NGS, and no statistically significant changes in $\mathrm{A} 1 \mathrm{G} 0 \mathrm{~F}$ secretion (Figures $4 \mathrm{~B}$ and $\mathrm{C}$ ). If UDP-GlcNAc availability were limiting, secretion of both these glycoforms would also be negatively impacted. Furthermore, the intracellular accumulation of UDP-GlcNAc, the increase in Man5 secretion, and the relative stability of G0F secretion imply that the rate limiting step is the reaction catalysed by the GnTI enzyme. The measured ranges for extracellular $\mathrm{pH}$ and ammonia concentration are below those that have been previously reported to impact the activity or Golgi localisation of GnTI (Borys et al. 1993; Gawlitzek et al. 2000; Rivinoja et al. 2009). The remaining possible cause for increased Man5 secretion in the least glucose-deprived cultures is the abundance of GnTI relative to specific mAb productivity (Figure S2). When considering this is the limitation, intracellular accumulation of UDP-GlcNAc is explained: a low GnTI to $q_{p}$ ratio in NGS and LGS reduces the rate of GlcNAc transfer onto Man5, and because less UDPGlcNAc is being consumed for this reaction, this NS accumulates within the cells.

In contrast to GlcNAc occupancy, production of galactosylated glycoforms (G1F and G2F, Figures $4 \mathrm{D}$ and E, respectively) increases with higher glucose starvation. No statistical differences were observed for G1F secretion before and after starvation for the HGS and SGS 
cultures, but a decrease of $1.5 \% \pm 0.3 \%$ was observed for NGS and LGS $(\mathrm{p}<0.05)$. In general, more G2F glycoform was produced during the starvation interval. However, a more pronounced increase in $\mathrm{G} 2 \mathrm{~F}$ secretion before and after starvation was observed for the HGS and SGS cultures $(\mathrm{P}<0.001)$. The above results are also clearly reflected in Gal occupancy (Figure 4, bottom row). Specifically, galactose occupancy was not affected for the HGS and SGS cases, but was observed to decrease for NGS and LGS $(\mathrm{p}<0.05)$.

When comparing galactose occupancy with intracellular UDP-Gal availability (Figure 2), we see a positive correlation. Higher intracellular UDP-Gal availability occurs for the most glucose starved cultures (HGS and SGS). In turn, these cultures present higher galactose occupancy during the starvation interval. The mechanisms underlying the interplay between intracellular UDP-Gal concentration, galactose occupancy and specific mAb productivity are consistent with the arguments put forth for GlcNAc. UDP-Gal accumulation in HGS and SGS is unlikely due to excess biosynthesis because these cultures were performed under considerable glucose limitation. Considering this, the most likely cause for intracellular UDPGal accumulation is that it is being consumed at a lower rate due to the low specific mAb productivity observed under these glucose starvation conditions (HGS and SGS). In turn, a lower $q_{p}$ also implies higher residence time within the Golgi apparatus which would allow for further processing of the mAb-bound glycans, leading to higher galactose occupancy.

\section{Effect of culture duration}

Appropriate harvest criteria need to be selected for mAb manufacture. Here, we analyzed the fed-batch culture at different time points and try to understand the balance between titer and quality of the mAbs in relation to the culture duration.

As shown in Figure $1 \mathrm{C}$, the specific productivity of mAbs was lower in early growth phase (slope 1 , day 2 to 5 ) comparing to that in late growth phase and early stationary phase (slope 2, day 5 to 9), which indicates there is an increase in $q_{p}$ after temperature shift. 
With regards to glycosylation (Figure 3 and Figure S1), it has been demonstrated by a trend of overall increases in Man5 and A1G0F, and decreases in G1F, G2F, and GlcNac and galactose occupancy along cultivation. This finding is in accordance with the apparent accumulation of UDP-GlcNAc and UDP-Gal during the cell culture as well (Figure 2).

More specifically, the most dramatic changes in glycoform distribution observed in this study occur between days 5 and 9 (Figure 3), where Man5 glycoform abundance increases by $11.6 \% \pm 0.3 \%$ and the G1F glycoform decreases by $11.9 \% \pm 0.7 \%$. The similarity between the changes in Man5 and G1F abundance is striking and is likely related: higher Man5 production leaves less glycoprotein substrate available for galactosylation during later stages of the glycosylation process within the Golgi apparatus. It is therefore possible that the drop in galactosylation is a direct consequence of high Man5 secretion.

A similar correlation (glycans become less processed with extended culture duration) has also been reported in other studies (Bibila and Robinson 1995; Hooker et al. 1995; Pacis et al. 2011; Robinson et al. 1994; Shi and Goudar 2014), which indicate that this could be a general phenomenon. Three major hypotheses have been proposed explaining such a phenomenon: (1) A bottleneck in the availability of nucleotide sugar substrates with respect to culture duration may exist (Hooker et al. 1995). However, this possibility can be ruled out in the NGS process, as the nucleotide sugar substrates such as UDP-GlcNAc and UDP-Gal were accumulated in the cells over time (Figure 2). (2) Cell death and lysis, may elevate the activity of extracellular glycosidase, especially sialidase in the culture, and thus increase the glycan degradation (Chee Furng Wong et al. 2005). However, it has also been demonstrated that $\mathrm{CHO}$-derived glycosidases including $\beta$-galactosidase, $\beta$-hexosaminidase may be less likely to contribute to the lower GlcNAc and Gal occupancy, since they exhibit very low activity at typical culture pH (Gramer and Goochee 1993). (3) Reduced expression or activity of Golgi-associated mannosidase and glycosyltransferases during the course of culture 
(Robinson et al. 1994) can lead to high mannose and low galactosylation. However, as reported previously, the changes in expression of GlcNAc transferase I (GnT1) during the course of a cell culture is cell line-dependent and do not show any general trend of decline (Fan et al. 2015; Pacis et al. 2011). Additionally, no apparent down-regulation was observed in the expressions of GlcNAc transferase II (GnTII) and various galactose transferases (GalT) along with increased culture duration (Wong et al. 2010a). Temperature shift may contribute to the decreases before and after day 5 in glycan maturation as a result of reduced activities of these enzymes. Additionally, Figure $1 \mathrm{C}$ also shows that the $q_{p}$ increases after the temperature shift on day 5 (slope 1 vs. slope 2). Therefore, it is possible that this increase in $q_{p}$ causes the decrease in glycoform complexity between 5 and 9 days of culture (This correlation is also indicated by Figure S2). If the abundance of GnTI relative to the $q_{p}$ goes below a certain level, lower GlcNAc occupancy will be achieved. These results point to the importance of considering the capability of glycosylation machinery available with respect to specific productivity. However, all the three major hypotheses do not completely explain the reported system-level data. Further investigations are needed in understanding the root cause of this type of glycosylation change.

\section{Comparative proteomics analysis between early growth phase and early stationary phase in fed-batch}

In order to gain insight into the fundamental differences in the cell culture from early growth phase to early stationary phase, in-depth analysis of proteome changes in cells from the two phases in the NGS process was performed.

In total across all samples, 5113 proteins were identified with FDR $<1 \%$ in the proteomics data (Table SIII), in which 4647 proteins were processed using gene set enrichment analysis (GSEA, Table SV). 3294 proteins were enriched into 228 and 334 gene sets using functional database and gene ontology database, respectively (Tables SVI and SVIII). Enrichment maps 
illustrating GSEA results were built. The enriched gene sets containing genes with statistically significant changes in protein level between early growth phase and early stationary phase were shown in Figure 5. Further leading-edge analysis (LEA) was performed using the output from GSEA (Supplementary material II). The top 10 up and down-regulated genes (Tables III and IV) and enriched gene sets (Tables SI and SII) from LEA were shown. Briefly, the genes in the gene sets with transcription, cell cycle and nucleotide metabolism related activity were generally expressed at higher level in early growth phase, which is consistent with the rapid cell growth during this phase. The majority of proteins encoded by these genes are located in nucleus (283 proteins).

On the other hand, the genes in the gene sets regarding glucose, lipid, and nucleotide sugar metabolism, environmental sensing and signal transduction, protein trafficking and secretion, extracellular matrix regulation, glycosylation and apoptosis related activity were up-regulated in early stationary phase. The proteins encoded by these genes are mainly located at membrane (262 proteins) and extracellular region (45 proteins).

Specifically, increasing environmental sensing and signal transduction related activity in early stationary phase involved a number of gene sets found in both databases. This implies that cells may be more sensitive to and tightly regulated upon environmental changes, for example media and process conditions in early stationary phase than in early growth phase. Another interesting point we found is that protein trafficking and secretion were more active in early stationary phase with regard to in early growth phase, as a large set of genes involved in this activity were up-regulated. Therefore, we suggest that the cellular machinery in relation to protein secretion was more active for cells in early stationary phase than in early growth phase. In contrast to that, genes in the gene sets regarding glycosylation related activity are very few, although they were shown to be up-regulated (Figure 5). 
Taking one step more, we further specifically analyzed the proteome involved in the secretion machinery (Table SXI), nucleotide sugar synthesis pathway (Table SXII) and biosynthesis pathway of N-glycans (Table SXIII).

The relative activation of secretion machinery during the early stationary phase has been demonstrated in (Table SXI). We found that 12 proteins were up-regulated in early stationary phase within our cut-off criteria. Out of the 12 proteins three (XP_007653021, XP_003499981 and XP_003512468) are directly related to protein transport in the cell and three (XP_003504664, XP_003501071 and XP_003507839) are responsible for protein folding. In contrast, only seven proteins were up-regulated in early growth phase within the cut-off criteria. Interestingly, three of them were heat-shock proteins (HSP), which may reflect the effect of temperature shift during the culture. It is also worth to mention that many of the HSPs are glycosylated (Baycin-Hizal et al. 2012), and the glycosylation of them might compete with recombinant protein glycosylation.

In the nucleotide sugar synthesis pathway, Proteins XP_007612718, NP_001233687 and XP_003515993 that are responsible for UDP-Glc and UDP-Gal biosynthesis were slightly up-regulated in early stationary phase (Table SXII). The expressions of NP_001233638 and XP_003514714 that can direct UDP-GlcNAc to UDP-GalNAc and N-Acetyl-Dmannosamine (ManNAc), respectively, were higher in early stationary phase. These results are in agreement with the findings above (Figure 5) that genes involved in nucleotide sugar metabolism were generally up-regulated in early stationary phase.

Regarding the biosynthesis pathway of N-glycans (Table SXIII), three proteins (XP_003500143, XP_003500900, XP_003508783) that are responsible for initiation of Nglycosylation in the ER were slightly up-regulated during early stationary phase. Very interestingly, the expression of only two protein $\alpha$-mannosidase II (XP_003499415) and 
GnT1 (NP_001230909) involved in glycan maturation in Golgi apparatus were slightly higher during early stationary phase.

Taken together, the essential causal link between producing the more processed glycans in early growth phase than in early stationary phase could be narrowed down to the following two possibilities: Firstly, it may be attributed to the overall capabilities of protein secretion machinery from early growth phase to early stationary phase in the cells gradually exceeding the capability of protein glycosylation machinery that is specifically responsible for glycan maturation (indicated by the proteomics data and the data of intervals day 0-5 and day 5-9 in Figure S2). Secondly, it is also possible that the activities of enzymes that raise GlcNac and Gal occupancy may be reduced due to certain environmental change and/or physiological response (e.g. temperature shift and/or $\mathrm{pH}$ gradient across the network of ER and Golgi apparatus) of the cells with the cultivation duration increased.

\section{Conclusion}

Using the multi-pronged omics-based approaches, we have shown here the effects of glucose starvation and culture duration on fed-batch $\mathrm{CHO}$ cell culture producing monoclonal antibody and the underlying reasons that cause such effects. Glucose starvation at early stationary phase of the fed-batch culture exhibited a negative impact on growth, viability, and specific productivity of the cells. It was also shown that the changes of glycoforms (increased GlcNAc and Gal occupancy) in regard to increased degree of glucose starvation are most likely as a result of interplay between the dilution effect associated with change in $q_{p}$ and the changed nucleotide sugar metabolism. On the other hand, the effect of culture duration on the glycopatterns is dramatic. In general, longer culture duration seems to generate a higher abundance of less processed glycan structures. Especially between samples from early growth phase (days 2 and 5) and early stationary phase (day 9), the extent of such effect is immense, which was thought to be correlated with the fundamental physiological difference between 
cells in the two phases. For that reason, we took one step further to examine the differences between proteome levels in these two phases. We found that the expression of proteins regarding cell cycle progression and cell divisions are generally up-regulated in early growth phase. On the other hand, expression of proteins that is responsible for regulating cellular metabolism, extracellular matrix, apoptosis, protein secretion and glycosylation is generally higher in early stationary phase. Very importantly, a large repertoire of proteins concerning secretion machinery was generally up-regulated in early stationary phase, whereas only two proteins ( $\alpha$-mannosidase II and GnT1) regarding glycan maturation in Golgi apparatus were found to be slightly up-regulated. In this way, we gained deeper insight into the culture behavior and recombinant protein production on the basis of the molecular features of the cells. From the process control perspective, this proteome information could help discover and apply knowledge of cellular functions in response to changes in process conditions, in order to explore possiblities of producing recombinant product with optimal productivity and quatlity.

We have not excluded the possibility of cell line specific effects on our data, and ideally different cell lines should be further investigated. However, the omics-based analysis constitutes a powerful tool for studying the physiological profiles of cells under different culture conditions and linking that with the quantity and quality of the recombinant product. 


\section{References}

Aggarwal K, Choe LH, Lee KH. 2006. Shotgun proteomics using the iTRAQ isobaric tags. Brief Funct Genomic Proteomic 5(2):112-20.

Ahn WS, Antoniewicz MR. 2013. Parallel labeling experiments with [1,2-(13)C]glucose and [U-(13)C]glutamine provide new insights into $\mathrm{CHO}$ cell metabolism. Metab Eng $15: 34-47$.

Baycin-Hizal D, Tabb DL, Chaerkady R, Chen L, Lewis NE, Nagarajan H, Sarkaria V, Kumar A, Wolozny D, Colao J and others. 2012. Proteomic analysis of Chinese hamster ovary cells. J Proteome Res 11(11):5265-76.

Bibila TA, Robinson DK. 1995. In pursuit of the optimal fed-batch process for monoclonal antibody production. Biotechnol Prog 11(1):1-13.

Borys MC, Linzer DI, Papoutsakis ET. 1993. Culture pH affects expression rates and glycosylation of recombinant mouse placental lactogen proteins by Chinese hamster ovary (CHO) cells. Bio/Technology 11(6):720-724.

Cao Y, Kimura S, Itoi T, Honda K, Ohtake H, Omasa T. 2012. Construction of BAC-based physical map and analysis of chromosome rearrangement in Chinese hamster ovary cell lines. Biotechnol Bioeng 109(6):1357-67.

Chee Furng Wong D, Tin Kam Wong K, Tang Goh L, Kiat Heng C, Gek Sim Yap M. 2005. Impact of dynamic online fed-batch strategies on metabolism, productivity and Nglycosylation quality in CHO cell cultures. Biotechnol Bioeng 89(2):164-77.

Dean J, Reddy P. 2013. Metabolic analysis of antibody producing CHO cells in fed-batch production. Biotechnol Bioeng 110(6):1735-47.

Druz A, Son YJ, Betenbaugh M, Shiloach J. 2013. Stable inhibition of mmu-miR-466h-5p improves apoptosis resistance and protein production in CHO cells. Metab Eng 16:8794. 
Fan Y, Jimenez Del Val I, Müller C, Wagtberg Sen J, Rasmussen SK, Kontoravdi C, Weilguny D, Andersen MR. 2015. Amino acid and glucose metabolism in fed-batch CHO cell culture affects antibody production and glycosylation. Biotechnol Bioeng 112(3):521-535.

Gagnon M, Hiller G, Luan YT, Kittredge A, DeFelice J, Drapeau D. 2011. High-end pHcontrolled delivery of glucose effectively suppresses lactate accumulation in $\mathrm{CHO}$ fed-batch cultures. Biotechnol Bioeng 108(6):1328-37.

Gawlitzek M, Ryll T, Lofgren J, Sliwkowski MB. 2000. Ammonium alters N-glycan structures of recombinant TNFR-IgG: degradative versus biosynthetic mechanisms. Biotechnol Bioeng 68(6):637-46.

Goetze AM, Liu YD, Zhang Z, Shah B, Lee E, Bondarenko PV, Flynn GC. 2011. Highmannose glycans on the $\mathrm{Fc}$ region of therapeutic $\operatorname{IgG}$ antibodies increase serum clearance in humans. Glycobiology 21(7):949-59.

Gramer MJ, Goochee CF. 1993. Glycosidase Activities in Chinese Hamster Ovary Cell Lysate and Cell Culture Supernatant. Biotechnol Prog 9(4):366-373.

Hooker AD, Goldman MH, Markham NH, James DC, Ison AP, Bull AT, Strange PG, Salmon I, Baines AJ, Jenkins N. 1995. N-glycans of recombinant human interferon- $\gamma$ change during batch culture of chinese hamster ovary cells. Biotechnol Bioeng 48(6):639-648.

Hossler P, Khattak SF, Li ZJ. 2009. Optimal and consistent protein glycosylation in mammalian cell culture. Glycobiology 19(9):936-49.

Hu WS, Dodge TC, Frame KK, Himes VB. 1987. Effect of glucose on the cultivation of mammalian cells. Dev Biol Stand 66:279-90. 
Huang da W, Sherman BT, Lempicki RA. 2009a. Bioinformatics enrichment tools: paths toward the comprehensive functional analysis of large gene lists. Nucleic Acids Res 37(1):1-13.

Huang da W, Sherman BT, Lempicki RA. 2009b. Systematic and integrative analysis of large gene lists using DAVID bioinformatics resources. Nat Protoc 4(1):44-57.

Jefferis R. 2012. Isotype and glycoform selection for antibody therapeutics. Arch Biochem Biophys 526(2):159-66.

Jimenez Del Val I, Kyriakopoulos S, Polizzi KM, Kontoravdi C. 2013. An optimized method for extraction and quantification of nucleotides and nucleotide sugars from mammalian cells. Anal Biochem 443(2):172-80.

Kildegaard HF, Baycin-Hizal D, Lewis NE, Betenbaugh MJ. 2013. The emerging CHO systems biology era: harnessing the 'omics revolution for biotechnology. Curr Opin Biotechnol 24(6):1102-7.

Kochanowski N, Blanchard F, Cacan R, Chirat F, Guedon E, Marc A, Goergen JL. 2008. Influence of intracellular nucleotide and nucleotide sugar contents on recombinant interferon-gamma glycosylation during batch and fed-batch cultures of $\mathrm{CHO}$ cells. Biotechnol Bioeng 100(4):721-33.

Lewis NE, Liu X, Li Y, Nagarajan H, Yerganian G, O'Brien E, Bordbar A, Roth AM, Rosenbloom J, Bian C and others. 2013. Genomic landscapes of Chinese hamster ovary cell lines as revealed by the Cricetulus griseus draft genome. Nat Biotechnol 31(8):759-65.

Lim Y, Wong NS, Lee YY, Ku SC, Wong DC, Yap MG. 2010. Engineering mammalian cells in bioprocessing - current achievements and future perspectives. Biotechnol Appl Biochem 55(4):175-89. 
Liu B, Spearman M, Doering J, Lattova E, Perreault H, Butler M. 2014. The availability of glucose to $\mathrm{CHO}$ cells affects the intracellular lipid-linked oligosaccharide distribution, site occupancy and the $\mathrm{N}$-glycosylation profile of a monoclonal antibody. J Biotechnol 170:17-27.

McGettigan PA. 2013. Transcriptomics in the RNA-seq era. Curr Opin Chem Biol 17(1):411.

Merico D, Isserlin R, Stueker O, Emili A, Bader GD. 2010. Enrichment map: a networkbased method for gene-set enrichment visualization and interpretation. PLoS ONE 5(11):e13984.

Pacis E, Yu M, Autsen J, Bayer R, Li F. 2011. Effects of cell culture conditions on antibody N-linked glycosylation —what affects high mannose 5 glycoform. Biotechnol Bioeng 108(10):2348-2358.

Pottiez G, Wiederin J, Fox HS, Ciborowski P. 2012. Comparison of 4-plex to 8-plex iTRAQ quantitative measurements of proteins in human plasma samples. J Proteome Res 11(7):3774-81.

Raju TS. 2008. Terminal sugars of Fc glycans influence antibody effector functions of IgGs. Curr Opin Immunol 20(4):471-8.

Rivinoja A, Hassinen A, Kokkonen N, Kauppila A, Kellokumpu S. 2009. Elevated Golgi pH impairs terminal N-glycosylation by inducing mislocalization of Golgi glycosyltransferases. J Cell Physiol 220(1):144-154.

Robinson DK, Chan CP, Yu Lp C, Tsai PK, Tung J, Seamans TC, Lenny AB, Lee DK, Irwin J, Silberklang M. 1994. Characterization of a recombinant antibody produced in the course of a high yield fed-batch process. Biotechnol Bioeng 44(6):727-735. 
Rouiller Y, Perilleux A, Collet N, Jordan M, Stettler M, Broly H. 2013. A high-throughput media design approach for high performance mammalian fed-batch cultures. MAbs 5(3):501-11.

Shi HH, Goudar CT. 2014. Recent advances in the understanding of biological implications and modulation methodologies of monoclonal antibody $\mathrm{N}$-linked high mannose glycans. Biotechnol Bioeng 111(10):1907-1919.

SPSS Inc. 2011. IBM SPSS Statistics for Windows. Armonk, NY: IBM Corp.

Subramanian A, Tamayo P, Mootha VK, Mukherjee S, Ebert BL, Gillette MA, Paulovich A, Pomeroy SL, Golub TR, Lander ES and others. 2005. Gene set enrichment analysis: A knowledge-based approach for interpreting genome-wide expression profiles. PNAS 102(43):15545-15550.

Templeton N, Dean J, Reddy P, Young JD. 2013. Peak antibody production is associated with increased oxidative metabolism in an industrially relevant fed-batch $\mathrm{CHO}$ cell culture. Biotechnol Bioeng 110(7):2013-+.

Wisniewski JR, Zougman A, Nagaraj N, Mann M. 2009. Universal sample preparation method for proteome analysis. Nat Methods 6(5):359-62.

Wong DC, Wong NS, Goh JS, May LM, Yap MG. 2010a. Profiling of N-glycosylation gene expression in CHO cell fed-batch cultures. Biotechnol Bioeng 107(3):516-28.

Wong NS, Wati L, Nissom PM, Feng HT, Lee MM, Yap MG. 2010b. An investigation of intracellular glycosylation activities in $\mathrm{CHO}$ cells: effects of nucleotide sugar precursor feeding. Biotechnol Bioeng 107(2):321-36.

Xie L, Nyberg G, Gu X, Li H, Mollborn F, Wang DI. 1997. Gamma-interferon production and quality in stoichiometric fed-batch cultures of Chinese hamster ovary $(\mathrm{CHO})$ cells under serum-free conditions. Biotechnol Bioeng 56(5):577-82. 
Xu X, Nagarajan H, Lewis NE, Pan S, Cai Z, Liu X, Chen W, Xie M, Wang W, Hammond S and others. 2011. The genomic sequence of the Chinese hamster ovary (CHO)-K1 cell line. Nat Biotechnol 29(8):735-41.

Young JD. 2013. Metabolic flux rewiring in mammalian cell cultures. Curr Opin Biotechnol 24(6):1108-15.

Zheng K, Bantog C, Bayer R. 2011. The impact of glycosylation on monoclonal antibody conformation and stability. MAbs 3(6):568-76.

\section{Figure legends}

Figure 1. Comparison of four fed-batch cultures with different levels of glucose starvation. Viable cell density, viability and integral of viable cells (IVC) vs. titer are presented in A, B and $\mathrm{C}$, respectively. Glucose, lactate and ammonia concentrations in the course of cell culture are shown in $\mathrm{D}, \mathrm{E}$ and $\mathrm{F}$, respectively. The error bars represent the standard deviation calculated from duplicate experiments. The average specific production $(+)$ or consumption (-) rate of glucose, lactate, glutamine, glutamate and ammonia from day 9 to day 12 were calculated as: $\mathrm{q}_{\mathrm{x}}=\frac{C_{\mathrm{X} \text { before }}^{\mathrm{day} 12}-C_{\mathrm{x} \text { after }}^{\mathrm{day} 9}}{\mathrm{IVC}^{\mathrm{day} 12}-\mathrm{IVC}^{\mathrm{day} 9}} \cdot C_{\mathrm{x} \text { after }}^{\text {day } 9}$ and $C_{\mathrm{x} \text { before }}^{\text {day } 12}$ are the concentration of nutrients or metabolites in the cell culture on day 9 after feeding and on day 12 before feeding, respectively. IVC ${ }^{\text {day9 }}$ and IVC ${ }^{\text {day12 }}$ are IVC on day 9 and day 12, respectively. Slope 1: from day 2 to day 5 ; slope 2 : from day 5 to day 9.

Figure 2. Intracellular nucleotide sugar analysis. Time course of concentration of intracellular nucleotide sugars (UDP-Glc, UDP-Gal, UDP-GlcNAc and UDP-GalNAc) from the cell cultures with different levels of glucose starvation were shown. Nucleotide sugar synthesis typically starts from degradation of glucose through glycolysis, in which glucose converts into glucose-6-phosphate and fructose-6 phosphate. Degradation of intracellular glucose generates Glucose-6-phosphate (Glc-6P), which is a critical substrate involved in 
glycolysis. Glc-6P can further become Fructose-6-pahospate (Fru-6P), which can enter into the TCA cycle for energy production, or together with glutamine supply biosynthesis of UDP-glucosamine (UDP-GlcNAc) and UDP-galactosamine (UDP-GalNAc. Alternatively, Glc-6P can turn into Glucose-1-phosphate (Glc-1P), which is responsible for generating UDP-glucose (UDP-Glc), UDP-galactose (UDP-Gal). In case of glucose starvation, lactate can be used as alternative carbon source to drive the TCA cycle. Once lactate is depleted, cells will mainly depend on using glutamine and other amino acids to support energy production and thus generate $\mathrm{NH} 4+$.

Figure 3. Glycoprofiles of mAbs produced from the cell cultures with different levels of glucose starvation. (A) Mannose 5, (B) A1G0F, (C) G1F and (D) G2F

Figure 4. Fraction of $\mathrm{mAb}$ glycoforms secreted before and during glucose limitation. The fraction of the Man5 (A), A1G0F (B), G0F (C), G1F (D) and G2F (E) glycoforms are presented for the intervals before ( 5 to $9 \mathrm{~d}$ ) and after (9 to $12 \mathrm{~d}$ ) of glucose limitation. Each bar represents the different conditions of glucose limitation during the day 9 to 12 period: NGS, LGS, HGS and SGS. The values shown correspond to means for duplicate $(n=2)$ cultures and statistical analysis was performed as described in the materials and methods. The criteria for significant differences are: $*$ for $\mathrm{p}<0.05, * *$ for $\mathrm{p}<0.01$ and $* * *$ for $\mathrm{p}<0.001$.

Figure 5. Enrichment map based on gene set enrichment analysis of comparative proteomics. The analysis has been done using (A) functional database and (B) gene ontology database, respectively. All enriched gene sets are represented as dots. The size of the dot indicates the size of the gene set. Red dot signifies the genes in that gene set is generally up-regulated in early growth phase (on day 2) of the fed-batch culture, whereas blue dot stands for general up-regulation of the genes in early stationary phase (on day 9). Overlapped genes between the two gene sets were shown as green line. The thickness of the green light represents the size of 
the overlapped genes. Further clustering of the enriched gene sets based on their descriptions was indicated using light blue circles. 
Table I. Culture performance and mAb production under glucose starvations. * Control.

\begin{tabular}{|c|c|c|c|c|c|c|c|}
\hline $\begin{array}{c}\text { Process } \\
\text { name }\end{array}$ & Description & Glutamine & Glutamate & Lactate & NH4+ & $\begin{array}{l}\text { Culture } \\
\text { process }\end{array}$ & $\begin{array}{c}\mathbf{m A b} \\
\text { production }\end{array}$ \\
\hline NGS* & No glucose starvation & Not consumed & Highly consumed & $\begin{array}{l}\text { Almost not } \\
\text { consumed }\end{array}$ & Consumed & Uninterrupted & Uninterrupted \\
\hline LGS & Low glucose starvation & Consumed & Highly consumed & $\begin{array}{c}\text { Consumed and } \\
\text { depleted }\end{array}$ & Produced & Uninterrupted & Reduced \\
\hline HGS & High glucose starvation & Highly consumed & Consumed & $\begin{array}{l}\text { Highly consumed } \\
\text { and depleted }\end{array}$ & $\begin{array}{l}\text { Highly } \\
\text { produced }\end{array}$ & Early-ended & Highly reduced \\
\hline SGS & Severe glucose starvation & Highly consumed & Consumed & $\begin{array}{l}\text { Highly consumed } \\
\text { and depleted }\end{array}$ & $\begin{array}{l}\text { Extremely } \\
\text { produced }\end{array}$ & Early-ended & $\begin{array}{c}\text { Extremely } \\
\text { reduced }\end{array}$ \\
\hline
\end{tabular}


Table II. Fraction of total mAb secreted during each time interval and for all glucose limitation cases. The values for $q_{p}$ (pg/cell/day) for each case and interval are presented in the parentheses.

\begin{tabular}{lllll}
\hline Time interval & NGS & LGS & HGS & SGS \\
\hline & & & & \\
\hline & $8.7 \% \pm 0.6 \%$ & $11.9 \% \pm 0.7 \%$ & $17.1 \% \pm 1.4 \%$ & $19.2 \% \pm 0.3 \%$ \\
& $(7.54 \pm 0.80)$ & $(7.60 \pm 0.68)$ & $(8.02 \pm 0.71)$ & $(7.99 \pm 0.05)$ \\
& $31.9 \% \pm 2.4 \%$ & $46.7 \% \pm 0.5 \%$ & $60.3 \% \pm 4.7 \%$ & $65.6 \% \pm 0.2 \%$ \\
& $(11.45 \pm 0.44)$ & $(11.86 \pm 0.14)$ & $(11.25 \pm 0.85)$ & $(11.09 \pm 0.30)$ \\
9 to $9 \mathrm{~d}$ & $34.5 \% \pm 2.1 \%$ & $35.5 \% \pm 1.6 \%$ & $22.6 \% \pm 3.2 \%$ & $15.2 \% \pm 0.5 \%$ \\
& $(12.13 \pm 1.23)$ & $(9.14 \pm 0.18)$ & $(6.74 \pm 0.93)$ & $(4.33 \pm 0.22)$ \\
& & & & \\
\hline & $24.9 \% \pm 0.3 \%$ & $5.9 \% \pm 1.8 \%$ & ---- & \\
\hline
\end{tabular}


Table III. Up and down regulated proteins on day 2 comparing to day 9 gene ontology

database using leading-edge analysis. H: Human; M: Mouse; E: Eukaryote; C: CHO; R:

Rat. "overlapped genes in Table IV.

\begin{tabular}{|c|c|c|c|c|c|}
\hline CHO RefSeq & Gene Symbol & Log2ratio & $\begin{array}{c}\text { Cells } \\
\text { studied }\end{array}$ & Function & Reference \\
\hline \multicolumn{6}{|l|}{ Up-regulated } \\
\hline NP_001233667 & TOP2A & 1.82 & $\mathrm{H}$ & Transcription, DNA replication & (Belluti et al. 2013) \\
\hline XP_003501907 & KPNA2 ${ }^{\#}$ & 1.63 & $\mathrm{H}$ & Cell proliferation, cell cycle & (Huang et al. 2013) \\
\hline XP_003510169 & KIF22 \# & 1.61 & $\mathrm{H}$ & Cell mitosis, cell cycle & (Yu et al. 2014) \\
\hline XP_003504632 & UBE2C $\#$ & 1.55 & $\mathrm{H}$ & Ubiquitylation, cell cycle & (Mocciaro and Rape 2012) \\
\hline XP_003499794 & DNMT1 & 1.53 & $\mathrm{H}$ & DNA replication & (Shimamura and Ishikawa 2008) \\
\hline XP_003500203 & LIG1 $\#$ & 1.39 & $\mathrm{H}$ & DNA repair, DNA replication & (Ferrari et al. 2003) \\
\hline XP_003504365 & HMGB2 & 1.36 & $\mathrm{H}$ & DNA repair & (Nagaki et al. 1998) \\
\hline XP_003499302 & KIF1A & 1.33 & M & Axonal transport & (Okada et al. 1995) \\
\hline XP_003509164 & KIF4A \# & 1.32 & $\mathrm{H}$ & Cell mitosis & (Mazumdar et al. 2004) \\
\hline XP_003500277 & MCM2 $\#$ & 1.25 & $\mathrm{E}$ & DNA replication & (Bell and Dutta 2002) \\
\hline \multicolumn{6}{|l|}{ Down-regulated } \\
\hline XP_003510318 & LGALS1 & -1.22 & $\mathrm{H}, \mathrm{M}$ & Apoptosis & (Scott and Weinberg 2002) \\
\hline XP_003510519 & ANXA1 \# & -1.27 & $\mathrm{H}, \mathrm{C}$ & Apoptosis; protein productivity & (Meleady et al. 2011; Wu et al. 2000) \\
\hline XP_003500109 & LGALS3 & -1.30 & $\mathrm{H}$ & Apoptosis & (Nakahara et al. 2005) \\
\hline XP_003515030 & COL5A2 ${ }^{\#}$ & -1.44 & $\mathrm{R}$ & Extracellular matrix regulation & (Liu et al. 2010) \\
\hline XP_003500579 & PLTP $^{\#}$ & -1.51 & $\mathrm{H}, \mathrm{C}$ & Lipid transfer & (Vuletic et al. 2009) \\
\hline XP_003504285 & COL7A1 ${ }^{\#}$ & -1.63 & $\mathrm{R}$ & Extracellular matrix regulation & (Liu et al. 2010) \\
\hline XP_003496178 & MMP12 & -1.69 & $\mathrm{C}$ & Extracellular matrix regulation & (Sandberg et al. 2006) \\
\hline XP_003515352 & FCGRT & -1.71 & $\mathrm{H}$ & IgG binding and protection & (Story et al. 1994) \\
\hline XP_003514816 & VAMP3 ${ }^{\#}$ & -1.74 & $\mathrm{H}$ & Protein secretion & (Kean et al. 2009) \\
\hline XP_003503110 & $\mathrm{PLG}^{\#}$ & -1.75 & $\mathrm{C}$ & Extracellular matrix regulation & (Rossignol et al. 2004) \\
\hline
\end{tabular}


Table IV. Up and down regulated proteins on day 2 comparing to day 9 found in

functional database using leading-edge analysis. H: Human; M: Mouse; E: Eukaryote; C:

CHO; " overlapped genes in Table III.

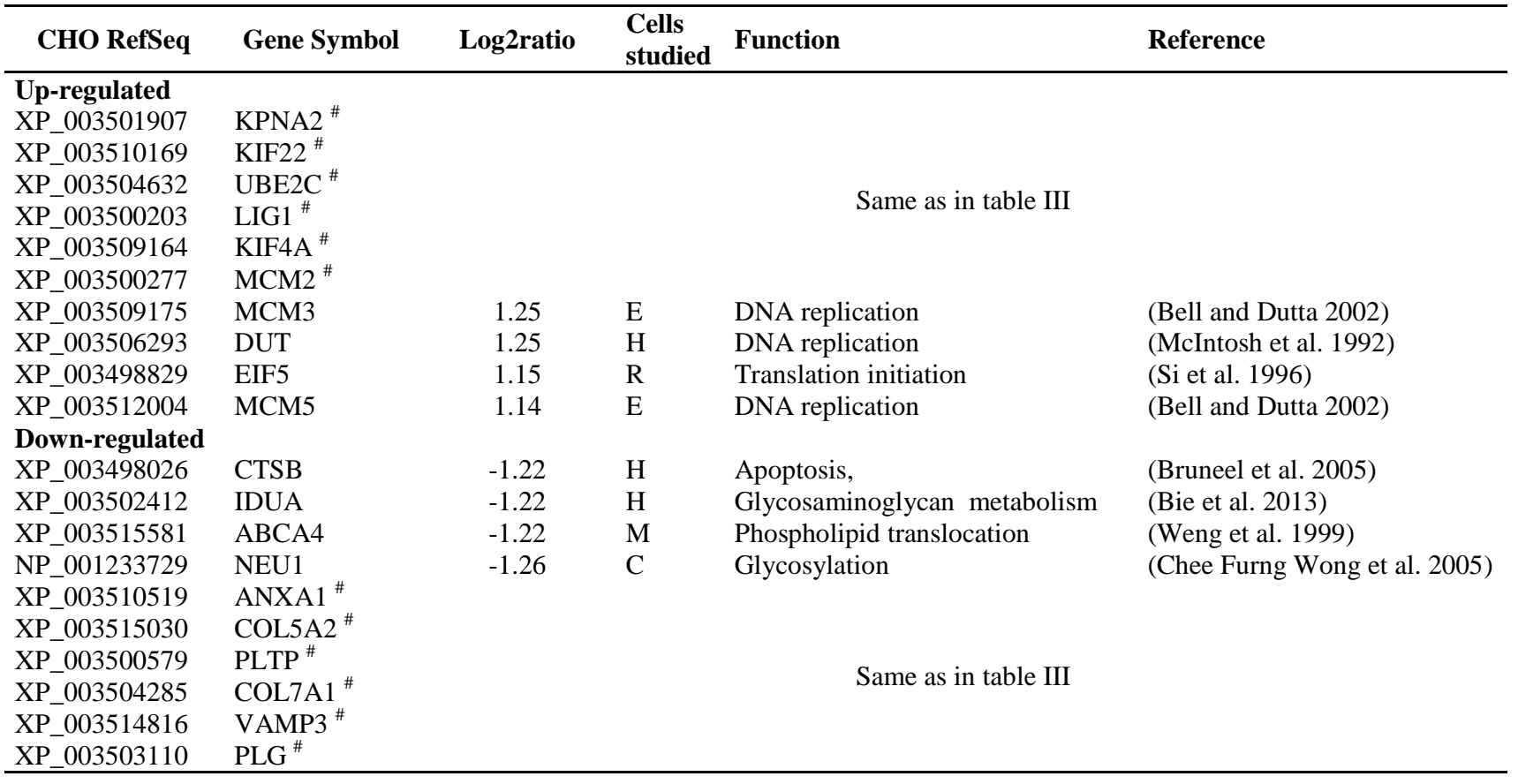


A

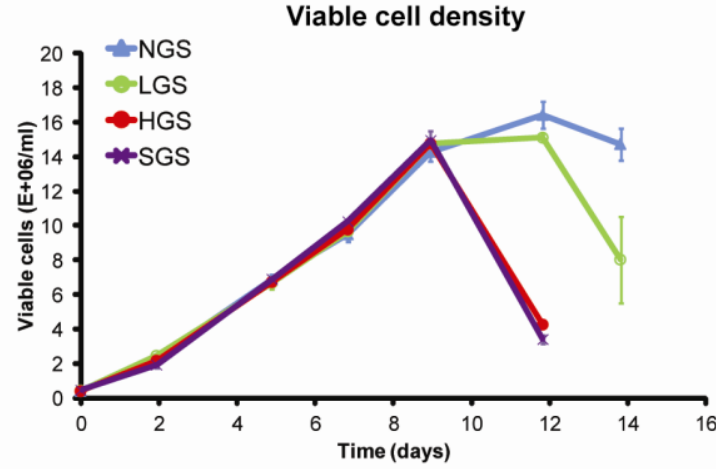

C
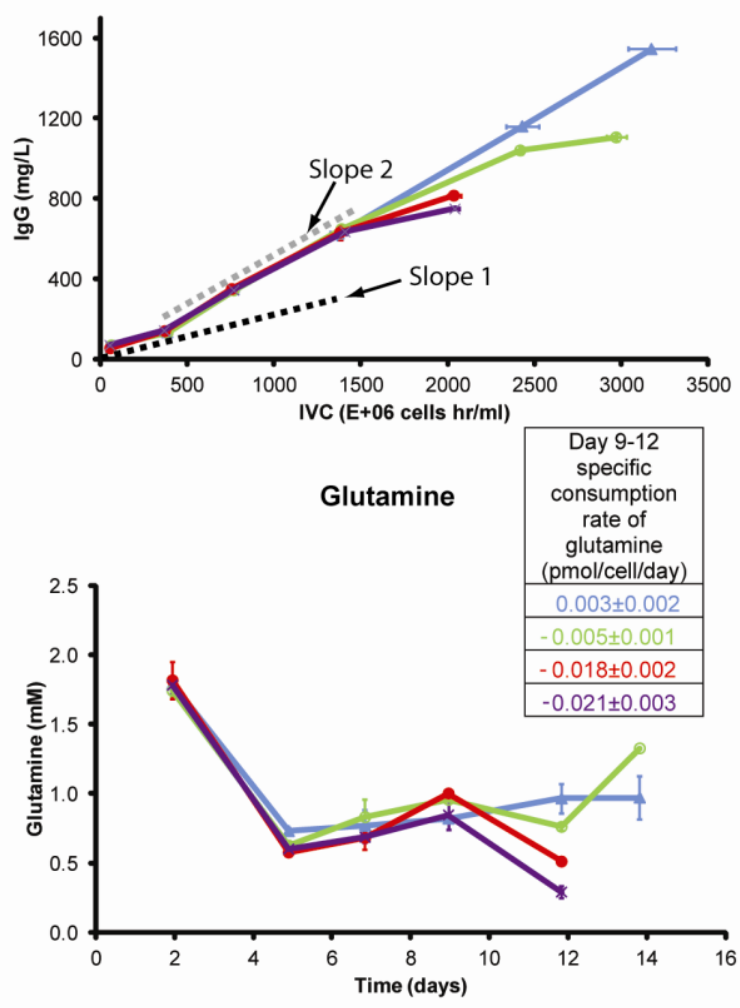

G

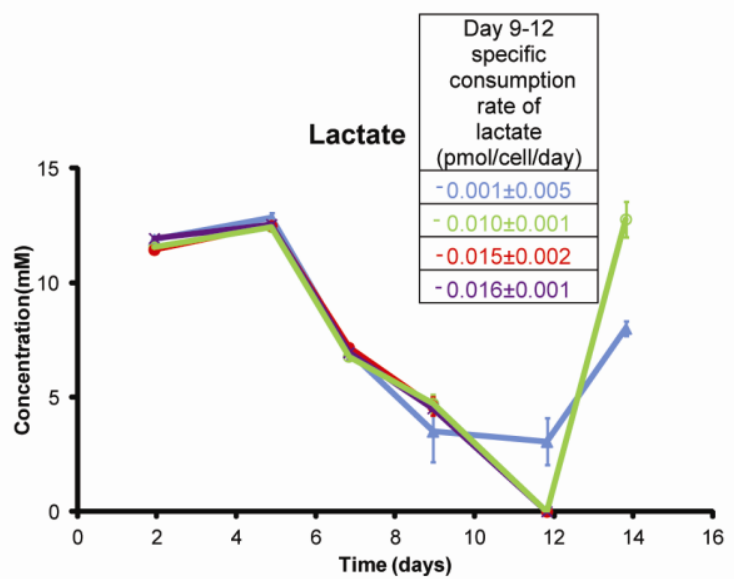

B

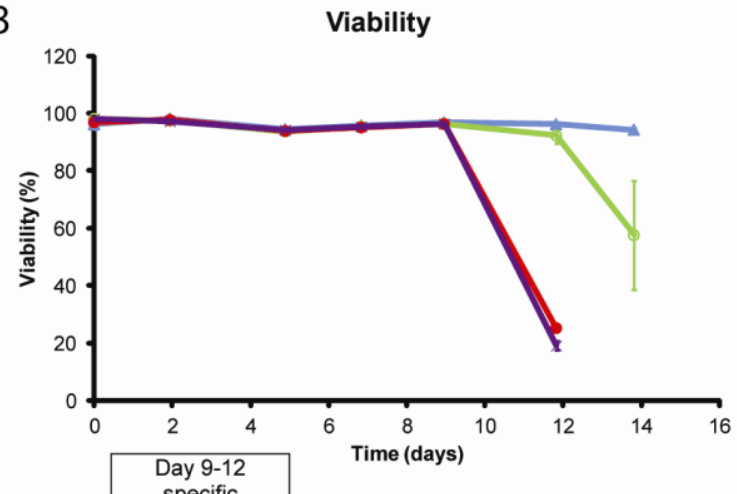

D
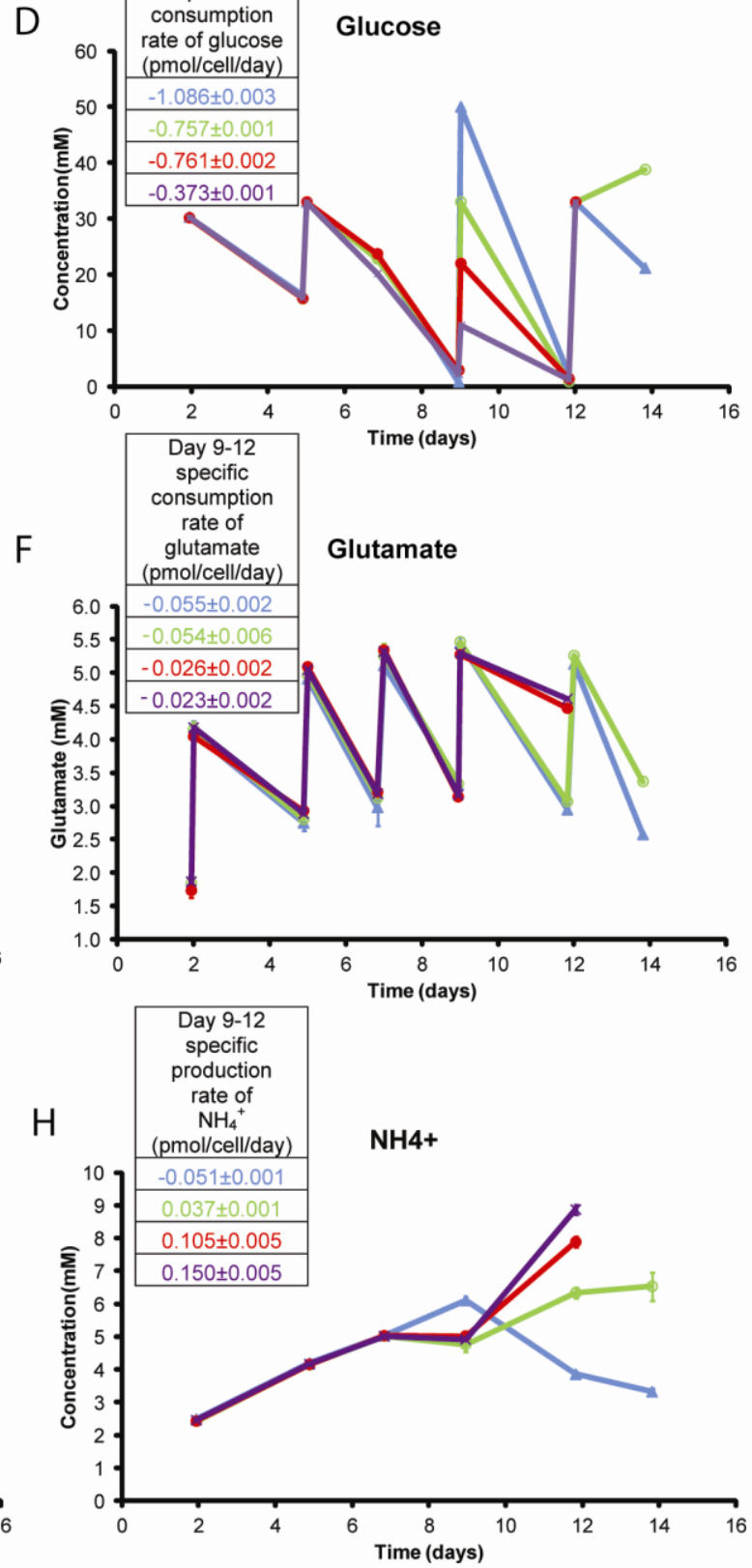

Figure 1

This article is protected by copyright. All rights reserved 


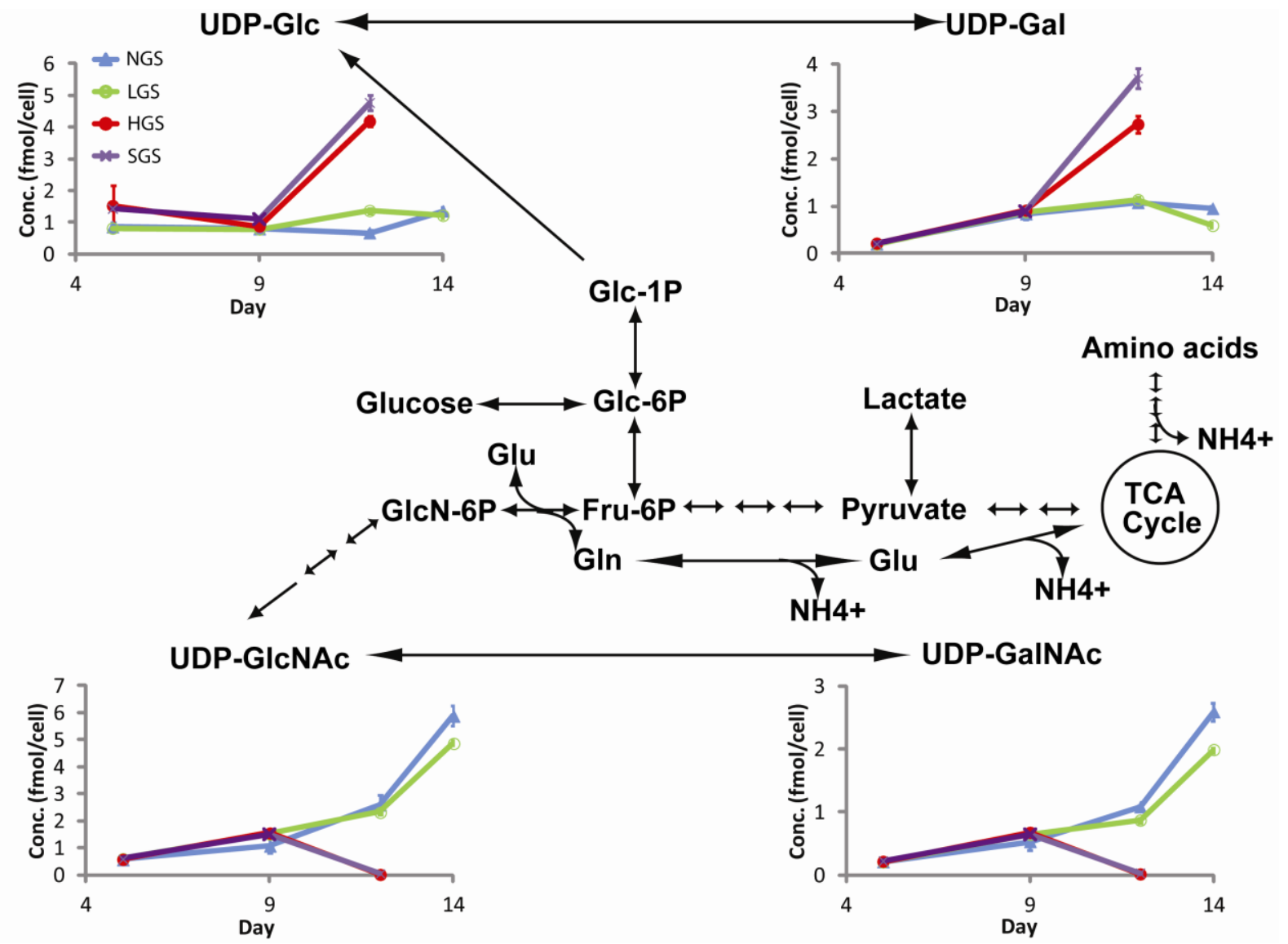

Figure 2 

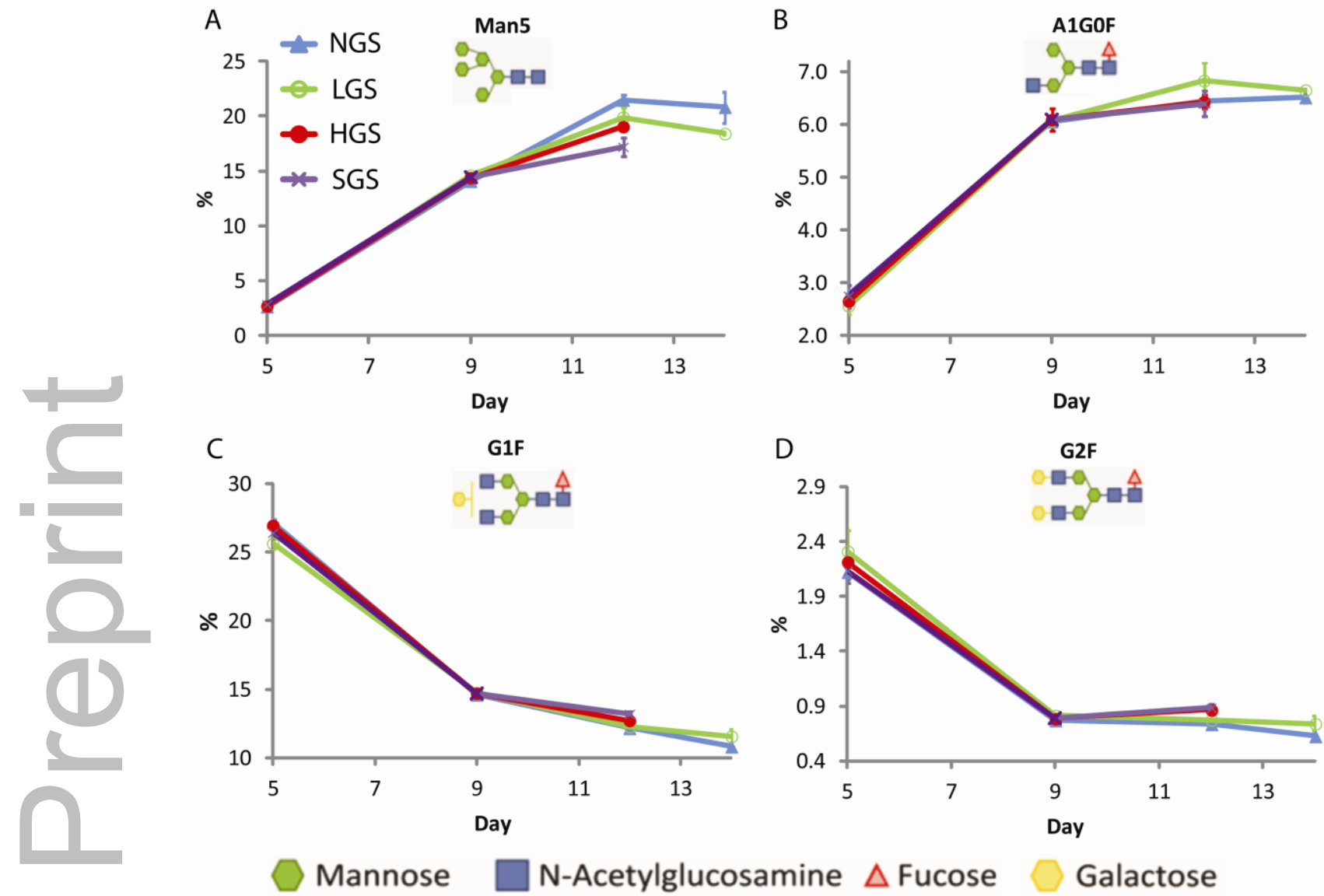

C

D

Figure 3

This article is protected by copyright. All rights reserved 

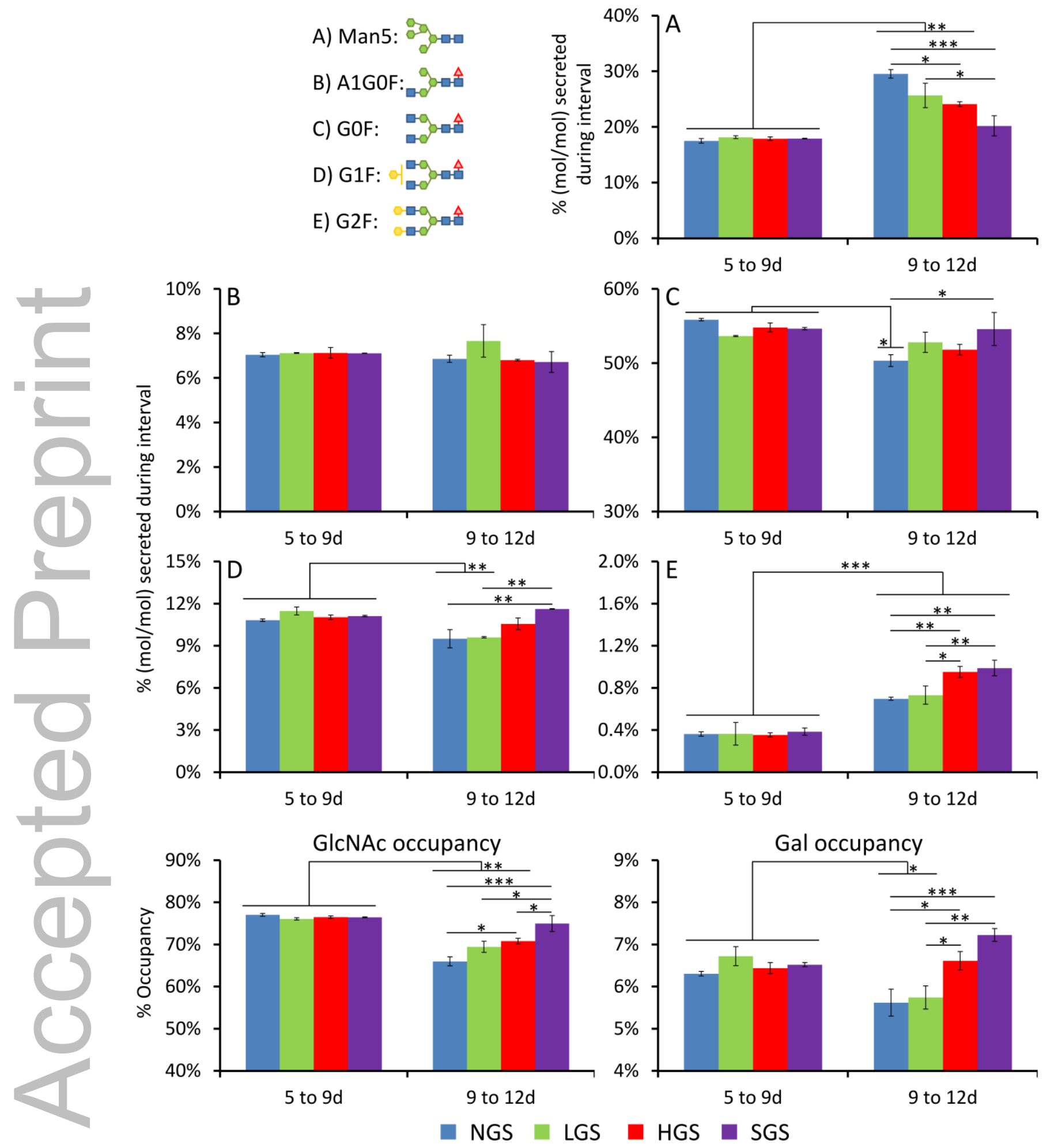

Figure 4

This article is protected by copyright. All rights reserved 

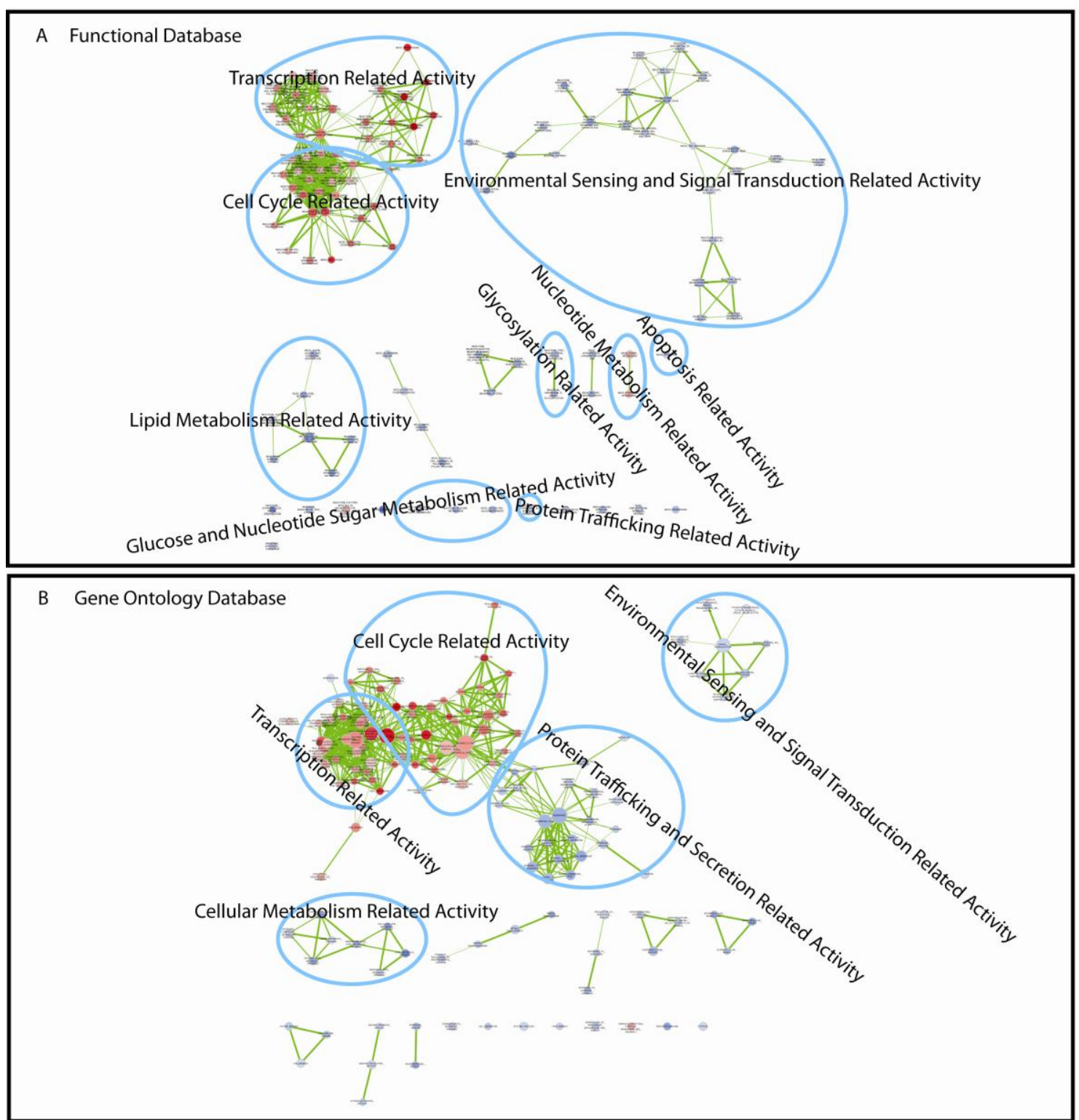

Figure 5 